\section{УДК 636.2.082.12:575.113}

https://doi.org/10.32634/0869-8155-2021-351-7-8-28-32

Краткий обзор/Brief review

Попов Н.А.

ФГБНУ ФИЦ ВИЖ им. Л.К. Эрнста, 142132, Московская область, г.о. Подольск, п. Дубровицы, д. 60

E-mail: genetic-pna@yandex.ru

Ключевые слова: голштинская порода, генеалогическая структура, быки-производители оценка племенной ценности, геномная оценка, оценка по качеству потомства, изменчивость, молочная продуктивность

Для цитирования: Попов Н. А. Генеалогическая структура и оценка быков-производителей голштинской породы. Аграрная наука. 2021; 351 (7-8): 28-32.

https://doi.org/10.32634/0869-8155-2021-351-7-8-28-320

Конфликт интересов отсутствует

Исследования проведены в соответствии с государственным заданием,

тема AАAА-A-18-118021590129-9

\section{Nikolai A. Popov}

L.K. Ernst Federal Research Center for Animal Husbandry, 60, Dubrovitsy village, Podolsk, Moscow Region, 142132

E-mail: genetic-pna@yandex.ru

Key words: Holstein breed, genealogical structure, sires, breeding value evaluation, genomic evaluation, offspring quality evaluation, variability, milk production

For citation: Popov N.A. Genealogical structure and evaluation of Holstein breeding bulls. Agrarian Science. 2021; 351 (7-8): 28-32. (In Russ.)

https://doi.org/10.32634/0869-8155-2021-351-7-8-28-32

There is no conflict of interests

\section{Генеалогическая структура} и оценка быков-производителей голштинской породы

\section{PE3ЮME}

Исследовалась генеалогическая структура состава быков-производителей голштинской породы на племенных предприятиях Российской Федерации ( $n=375)$, соотношение видов подбора при их выведении, а также параметры геномных оценок при их выведении в странах-экспортерах. Проведена оценка 21 быка-производителя по качеству дочерей и сравнение молочной продуктивности с их матерями в стаде племенного завода. Выявлен узкий спектр генеалогических линий у импортных голштинов, который не позволяет эффективно использовать генетическую изменчивость при совершенствовании скота отечественных популяций. Оценка быков по качеству потомства выявила распределение дочерей со смещением по признакам «удой» и «массовая доля белка (МДБ)» в сторону улучшения в стаде, но со снижением массовой доли жира (МДЖ) относительно групп матерей. Определение коэффициентов повторяемости и ранжирование по признакам молочности групп дочерей обнаружило значительные расхождения с показателями величин геномных оценок их отцов: по удою $r_{s}=0,395$, по МДБ $-r_{s}=0,200$ и по МДж $-r_{s}=-0,570$. Автор делает вывод о невозможности планирования совершенствования главных признаков селекции в стаде при отборе быков-производителей по уровням показателей геномных оценок и дает предложения по совершенствованию методики оценки быков-производителей по качеству потомства в молочном скотоводстве Российской Федерации.

\section{Genealogical structure and evaluation of Holstein breeding bulls}

\section{ABSTRACT}

The Holstein bulls' genealogical structure on the Russian Federation breeding enterprises ( $n=375$ ), as well as the selection types ratio of their breeding, genomic parameters' assessments in the countries of exporting were studied. The evaluation of 21 breeding sires on their daughters quality and their mothers milk production comparison in the breeding plant's herd was carried out. A narrow range of genealogical lines of imported Holsteins, that does not allow genetic variability's effective use at domestic livestock populations improvement, has been identified. These bulls evaluation by the offspring quality revealed the distribution of daughters on milk yield terms and the mass fraction of protein (PC) at the herd improvement, but with the mass fat fraction (FC) decreasing relative to the groups of mothers. The determination of the daughter groups' repeatability coefficients and ranking based on the milk production characteristics revealed significant differences with the genomic values estimated fortheir fathers: for milk yield $r_{s}=0,395$, for $\mathrm{PC}-r_{s}=0,200$, and for $\mathrm{FC}-r_{s}=-0,570$. The author concludes that it is impossible to plan improvement ofthe main features of breeding in herd at breeding bulls selecting according to the genomic assessment indicators' levels and givessuggestions for improvment of methodology of evaluating breeding sires by the quality of offspring in dairy cattle breeding of the Russian Federation.
Received: 10 June

Revised: 15 June

Accepted: 10 August 


\section{Введение}

Прогресс по признакам молочности в породе во многом зависит от совершенствования и точности оценки быков-производителей по качеству потомства. Во многих странах ученые, помимо изменения подходов $\mathrm{k}$ методике ее проведения, пересматривают вопросы отбора в группы «матерей быков», «отцов быков», а также аспекты изменения числа признаков и порядка их учета у дочерей. Проверяемые быки несут с собой риск снижения темпов улучшения количественных признаков и затрудняют направленную генеалогическую структуризацию племенных стад, связанную с поступлением «случайного» быка, а его потомки могут долго использоваться в ведущих племенных заводах породы.

Ускоряет эволюционный процесс распространение генофонда из зарубежных популяций, появление молодых быков-производителей, с повышенной «рекламной» племенной ценностью по отдельным востребованным признакам. Это склоняет зоотехников-селекционеров молочных ферм к более интенсивному использованию таких быков до официальной оценки по качеству потомства [1, 2]. В этой связи возрастает значимость использования поправок к величинам показателей, на которые влияют сезон, возраст, год, условия хозяйства, действуют факторы акклиматизации и в полной мере возрастает роль BLAD-процедуры по правилам, которые были определенны поправками к оценке быков-производителей 1996 года [3, 4].

Особенно активные процессы протекают при оценке племенных качеств быков-производителей в широко распространенной голштинской породе. Ее численность увеличивается за счет перевода в голштины поголовья стад ряда хозяйств, ранее относимых к черно-пестрой породе, без изменения их статуса как племенных.

Цель работы состояла в определении генетической и фенотипической изменчивости в стадах голштинской породы Российской Федерации при совершенствовании признаков молочности с использованием импортных быков-производителей и их оценкой разными методами.

\section{Задачи работы:}

- изучить структуру видов подбора при выведении быков-производителей по основным странам-экспортерам;

- оценить признаки молочной продуктивности дочерей-первотелок в сравнении с матерями и сверстницами по группам проверяемых быков-производителей в племенном стаде

- определить достоверность показателей племенной ценности по геномной оценке быков-производителей и возможность коррекции организации племенных оценок в высокопродуктивных стадах.

\section{Материал и методы исследований}

Изучались родословные 375 быков-производителей зарубежной селекции голштинской породы по данным каталогов племенных предприятий Российской Федерации. В системе практической селекции племенного стада ФГУП «Пойма» в 2018-2020 гг. контролировалось проведение оценок 37 быков-производителей по качеству потомства, из них в 2019 году 21 бык имел по 10 и более дочерей с законченной лактацией. Параметры показателей сверстниц дочерей и матерей определяли по данным первичного зоотехнического учета, а средние величины вычисляли с использованием программы СЕЛЭКС (ООО «РЦ «Плинор"»). Отбор и подбор быков-производителей в стаде осуществлялся по авторским методикам $[5,6]$, величины индексов генетической ценности в популяции - по признакам (Б) [7]. Ранжирование по удою, МДЖ и МДБ проводилось согласно величинам оценок по геному, определенных специалистами Канады, и фактических средних показателей в стаде дочерей и разностей «дочери - матери». Коэффициенты ранговой корреляции вычисляли по 21 классу (удой) и 14 классам - МДЖ и МДБ. Уровни коэффициентов наследуемости соответствовали периоду выполнения Программы селекции.

\section{Результаты исследований и их обсуждение}

Весьма важно оценивать генетическую изменчивость в генеалогической структуре популяций молочных пород $[6,8]$. После определения наиболее надежных генетических маркеров в линиях и семействах племенных заводов целесообразно своевременно принять стратегию по интенсивному использованию лучших быков, в том числе из групп «отцов быков» и молодых с учетом их боковых родственников, ускоряя ротацию в генеалогических группах и наращивая поголовье дочерей для более объективной оценки их отцов по качеству потомства.

Подбор быков-производителей в условиях ограниченности выбора по генеалогической структуре все более усложняется. По данным Е.И. Саксы и Van Raden [9, 10] в США оценивались $38,9 \%$ быков-производителей, выведенных внутрилинейно, и 71,4\% - кроссом - с участием только двух линий В.Б. Айдиала 933122 и Р. Соверинга 198998.

У поступивших на племпредприятия Подмосковья из Канады быков в этом соотношении преобладали также кроссы: 65,4\% к 34,6\%, а среди импортных из Голландии и Германии - 59, $1 \%$ к 40,3\%. У импортного поголовья из европейских стран встречались единичные варианты, когда они также выводились кроссом и внутрилинейным подбором, но дополнительно с участием линий П. Говернера 882933 и М. Чифтейна 95679. За последние 10 лет на племпредприятиях доминировало поголовье кроссированных и внутрилинейных быков-производителей двух линий В.Б. Айдиала 933122 и Р. Соверинга 198998 с обоюдными равнопредставленными кличками отцовских предков из ветвей этих же линий как с левой, так и с правой сторон родословных.

Вероятно, это послужило причиной отсутствия какого-либо значительного преобладания молочной продуктивности дочерей отцов, которые были выведены от кроссов линий и от внутрилинейных подборов. В США разница составила 51 кг, а в хозяйствах Ленинградской области - 65 кг в пользу потомства отцов, кроссированных по двум линиям. При удоях за стандартную лактацию коров-первотелок в ЗАО «Рабитицы» 10146 кг $(n=1075)$ от дочерей по линии Р. Соверинга при внутрилинейных подборах получено на 280 кг молока больше, а в США - на 177 кг [3, 9]. Разницы статистически недостоверные, поэтому все указывает на сглаживание генеалогических и генетических различий между двумя линиями, а также на увеличение однородности поголовья и по другим факторам. Можно предположить, что аналогичное продолжение сближения линий в последующем не позволит зоотехническими методами обнаруживать достаточно значимые фенотипические различия у потомства.

Измениться ли отношение к роли оценки по качеству потомства и предлагаемых вариантов прогнозируемых оценок племенной ценности для молодых быков-произ- 
водителей? Несомненно, к новым подходам оценок племенных качеств животных и поиску вариантов наиболее точных предварительных оценок специалисты особенно внимательны и будут возвращаться к ним постоянно

В таблице представлены оценки быков-производителей в стаде ФГУП «Пойма» по дочерям, закончившим первую лактацию в 2019 году [11, 12]. Все они, кроме Яголда-М, имели геномную оценку, данную специалистами Канады. Была определена их племенная ценность, которая выражена частью величины генетической ценности быка-производителя (Б) по признакам удоя, МДЖ и МДБ у дочерей согласно величинам $h^{2} \cdot(Д-$ М) + (Д - С) [7]. Большинство этих быков по характеристикам отбора существенно превосходят средние показатели коров стада. Однако существующая в стаде коров изменчивость обусловила распределение показателей первотелок по нормальному куполообразному профилю. Средние величины оценок групп отцов оказались сдвинуты относительно друг друга вдоль оси абсцисс.

В своем большинстве молодые быки из Канады относительно матерей дочерей улучшили показатели удоев и МДБ, но в такой же степени снизили содержание жира в молоке у дочерей.

Казалось бы, ничего необычного нет, все как и 20 лет тому назад. Однако направления и темп ухудшения либо улучшения величин по геномной оценке, определенных относительно канадских популяций голштинской породы, «шагали» далеко не в ногу с фактическими показа- телями дочерей в племенном стаде ФГУП «Пойма». Согласно коэффициентам повторяемости, их совпадение со средними показателями дочерей по удоям составило только 23,9\%, по МДЖ - 22,9\% и по МДБ - 39,3\%. Получено соотношение близко тому, когда геномной оценки не существовало, а быки отбирались согласно родословным и продуктивности, или «случайно» по сравнению с ультрасовременными подходами.

Нами были скорректированы величины племенной ценности быков $[13,14]$ по фактическим показателям дочерей относительно матерей и сверстниц. Их коэффициенты ранговой корреляции в сравнении с показателями геномных оценок оказались следующими: по удою $r_{s}=0,395$; по МДБ $-r_{s}=0,200$; по МДЖ - отрицательное значение, $r_{s}=-0,570$. При сопоставлении векторов и собственно фактических величин признаков по группам дочерей геномным оценкам отцов для специалистов хозяйств становится понятным отсутствие какой-либо зоотехнической значимости геномных оценок, ошибочность использования отбора по ним быков-производителей в стаде. Величины зарубежных геномных оценок, размещенные в каталогах, вводили селекционеров в заблуждение и являлись крайне ненадежными при планировании совершенствования признаков молочности коров.

Если селекционер доверился бы данным геномных оценок, для распределения по фермам ФГУП «Пойма», например, отбору подлежали бы только пара бы-

Таблица. Геномная оценка и фактические данные по потомству быков-производителей ФГУП «Пойма», 2019 г.

Table. Genomic assessment and actual data on the offspring of bulls-producers of FSUE "Poyma", 2019

\begin{tabular}{|c|c|c|c|c|c|c|c|c|c|c|}
\hline \multirow{2}{*}{$\begin{array}{l}\text { № } \\
\Pi / \Pi\end{array}$} & \multirow{2}{*}{$\begin{array}{c}\text { Кличка, инд. № } \\
\text { быка-производителя }\end{array}$} & \multicolumn{3}{|c|}{ Геномная оценка } & \multicolumn{3}{|c|}{$h^{2} \cdot(Д-M)+(Д-C)$} & \multicolumn{3}{|c|}{ \pm к сверстницам } \\
\hline & & по удою, кг & по Мдж, \% & по МДБ, \% & по удою, кг & по МдЖ, \% & по МдБ, \% & по удою, кг & по мдж, \% & по МДБ, \% \\
\hline 1 & Браулер 106303136 & 1609 & 0,10 & 0,08 & 1464 & 0,01 & 0,03 & 314 & 0,02 & 0,01 \\
\hline 2 & Стенли-М 11373104 & 2228 & $-0,11$ & 0,07 & 2263 & $-0,05$ & 0,03 & 1112 & 0,03 & 0,03 \\
\hline 3 & Браслет 106759921 & 641 & 0,10 & 0,14 & 1371 & $-0,05$ & 0,03 & 455 & 0,02 & 0,02 \\
\hline 4 & О. Локман-М 11098685 & 1824 & 0,25 & 0,25 & 1240 & 0,02 & 0,01 & -51 & 0,08 & 0,00 \\
\hline 5 & Пончо 11492044 & 1473 & 0,24 & 0,19 & 1761 & $-0,08$ & 0,01 & 704 & 0,01 & 0,01 \\
\hline 6 & К. Лоди-М 106739756 & 1008 & 0,22 & 0,14 & 1075 & 0,00 & 0,00 & 427 & 0,06 & 0,00 \\
\hline 7 & Урбант-М 11678053 & 1202 & 0,34 & 0,06 & 1303 & $-0,06$ & 0,01 & 571 & 0,01 & 0,01 \\
\hline 8 & Фокстрот-М 470345 & 410 & 0,12 & 0,14 & 1058 & $-0,04$ & 0,03 & 39 & 0,02 & 0,01 \\
\hline 9 & Баннер 106303118 & 1609 & 0,10 & 0,08 & 861 & $-0,02$ & 0,02 & 414 & $-0,02$ & 0,01 \\
\hline 10 & Атвуд 106303284 & 435 & 0,29 & 0,11 & 680 & $-0,02$ & 0,01 & 159 & 0,02 & 0,00 \\
\hline 11 & Гарсон 106739655 & 1559 & 0,09 & 0,00 & 1288 & $-0,08$ & $-0,02$ & 131 & $-0,01$ & 0,00 \\
\hline 12 & В. Бой-М 11373124 & 754 & 0,42 & 0,25 & 687 & $-0,06$ & 0,01 & 215 & $-0,02$ & 0,00 \\
\hline 13 & Презент 105586572 & 1244 & $-0,31$ & $-0,13$ & 757 & $-0,06$ & $-0,01$ & 197 & 0,00 & $-0,01$ \\
\hline 14 & Мишрет 106070030 & 992 & 0,32 & 0,19 & 654 & $-0,12$ & 0,04 & -57 & $-0,02$ & 0,03 \\
\hline 15 & Ж. Матадор-М 11087652 & 1559 & 0,09 & 0,00 & 1288 & $-0,08$ & $-0,02$ & 102 & $-0,17$ & $-0,06$ \\
\hline 16 & Диксон-М 11431151 & 2787 & 0,44 & 0,10 & -1486 & $-0,03$ & 0,02 & -1152 & 0,03 & 0,02 \\
\hline 17 & Джоли 106182935 & 889 & 0,27 & 0,25 & 319 & $-0,07$ & 0,00 & -292 & 0,00 & $-0,01$ \\
\hline 18 & Макентош 11011916 & 834 & 0,19 & $-0,03$ & 591 & $-0,11$ & 0,01 & -151 & $-0,02$ & 0,01 \\
\hline 19 & Оптимист 106301320 & 918 & 0,32 & 0,12 & -255 & $-0,03$ & $-0,02$ & -395 & 0,05 & $-0,01$ \\
\hline 20 & Яголд-М 468513 & 1194 & $-0,31$ & $-0,01$ & 168 & $-0,08$ & 0,00 & -315 & $-0,02$ & 0,00 \\
\hline 21 & Джилет 9862983 & -348 & 0,09 & 0,11 & -353 & $-0,17$ & 0,01 & -637 & $-0,07$ & 0,00 \\
\hline
\end{tabular}

Примечание. * Быки-производители расположены в последовательности, определенной минимальным числом суммы рангов, присвоенных по величинам, данным в колонках $6+7+8$. 
ков-производителей (I пара) Диксон-М (л. В.Б. Айдиала 933122, ветви Манфреда 2183007) и Оптимист (л. Р. Соверинга 198998, ветви А. Ротейта 1697572) с превосходными геномными характеристиками, соответственно +2787 кг; +0,44\%; +0,10\% и +918 кг; +0,32\%; +0,12\%. И таким образом были бы исключены им равнозначные по предварительной геномной оценке (II пара) Стенли-М (л. Р. Соверинга 198998, ветви Блекстара 1929410) и О. Лакман-М (л. В.Б. Айдиала 933122, ветви Манфреда 2183007), соответственно +2228 кг; $-0,11 \% ;+0,07 \%$ и +1017 кг; +0,36\%; +0,27\% [11, 12], то спустя 4 года имели бы диаметрально противоположные фактические показатели у дочерей:

I пара: -1486 кг; -0,03\%; +0,02\% и -225 кг; -0,03\%; $-0,02 \%$;

II пара: +2236 кг; -0,05\%; +0,03\% и +1240 кг; +0,02\%; $+0,01 \%$.

И это фактически полученный результат при равных величинах геномных оценок быков-производителей, купленных в Канаде.

Минимизации фактора "случайного» быка-производителя можно добиться направленным (индивидуальным) его подбором к маткам стада с целью проявления лучших характеристик его предков. К этому следует добавить выполнение условий по расширению числа стад, в которых оценивается молодой бык. Зоотехники-селекционеры владеют разноплановыми вариантами подборов и реализуемыми схемами для решения практических задач Программ селекции на отдельных этапах работы со стадами. В общем при увеличении числа хозяйств и потомков уменьшается доля субъективизма и увеличиваются достоверность и точность информации по потомкам в племенных стадах.

Коррекцию методики [13] необходимо увязывать с направленным точечным подбором, а не со случайным, руководствуясь сжатыми сроками. Выделенных коров целесообразно осеменять по мере прихода в охоту после отела. Таким образом решается вопрос контроля уровня инбридинга $[15,5]$ и увеличения представитель-

\section{БИБЛИОГРАФИЯ}

1. Herbut Piotr Forming of temperature-humidity index (THI) and milk production of cows in the free-stall barn during the period of summer heat / Piotr Herbut, Sabina Angrecka // Animal Science Papers and Reports.- 2012.- Vol.30(4).- P.363-372.

2. Карликов Д.В. Совпадаемость оценок импортных быков молочных пород по родословной и качеству потомства / Д.В. Карликов // В сб. «Совершенствование племенных и продуктивных качеств отечественных пород скота».- М.:ВНИИПлем, 1993. - С.96-103.

3. Сакса Е.И. Эффективность использования быков, оцененных разными методами, при совершенствовании высокопродуктивных стад / Е.И. Сакса // Молочное и мясное скотоводство. - 2018. - №1.- С.5-9.

4. Feedlot performance and carcass quality of spring finished Holstein steers fed whole corn and pelleted supplement with or without access to long hay / H. Chester-Jones, D.M. Ziegler, G.L. Dobberstein, P.T. Anderson // Minnesota Beef Res. Rpt.: Univ. Of Minnesota, St. Paul.- 2012.- B-401.- P.42-47.

5. Методические наставления по отбору быков-производителей черно-пестрой породы для повышения уровня молочной продуктивности и качества молока коров / Н.А. Попов, А.Н. Попов, Л.К. Марзанова, В.Ю. Сидорова.- Дубровицы: ГНУ ВИЖ Россельхозакадемии, 2013.- 72с.

6. Методические рекомендации «Оптимизация подбора в стадах молочного крупного рогатого скота» / Н.А. Попов, Л.К. Марзанова, В.Ю. Сидорова.- Дубровицы: ГНУ ВИЖ Россельхозакадемии, 2008.- 48c

7. Методические указания по оценке реализации признаков роста, развития и молочной продуктивности у потомков ства маток популяции, т. е. суммируются факторы «случайностей» по шести и более хозяйствам.

\section{Заключение}

В отечественной научной литературе не встречается работ, связанных с построением в популяциях голштинской породы нашей страны собственной генеалогической структуры. Продолжают вести ветви достаточно «старых» линий из стран-родоначальниц этой породы. Не случайна трактовка определений «генетической ценности быков», «разведения по линиям» приобретает «ультрасовременный» оттенок, теоретически не аргументированный научными исследованиями. Например, в 80-х годах прошлого столетия в СССР экспериментально было доказано, что быки-производители из Канады и США улучшают удой коров черно-пестрой породы [2, 14]. Но это утверждение равным образом не может относиться к категории «оценка быков по качеству потомства»! То есть насаждаемые предложения об отмене разведения по линиям ложны; они обосновываются «обнаружением» (?!) факторов значимого влияния отдельных быков-производителей на увеличение трендов признаков селекции у каждой подбираемой особи, а не по линиям в целом, и на мой взгляд, несвоевременны. Эти предложения ошибочно исключают необходимость учета генетической изменчивости в породе.

Значение предварительных прогнозов ценности молодых быков нередко весьма поспешно ставится выше, чем собственная «главная» их оценка по качеству потомства. «Товароведы» используют величины геномных оценок как «рыночные показатели», в том числе проводят расчеты по стоимости спермодозы. Внесение таких предварительных оценок в каталоги быков региональных племенных предприятий по искусственному осеменению целесообразно исключить, но при этом следует разрабатывать новые оценки, сопряженные с генеалогической структурой голштинской породы [8, 16].

Несомненно, следует углублять исследования и совершенствовать оценку животных в этих направлениях, т. к. сейчас она не бесспорна и далеко не однозначна.

быков-производителей / Н.А. Попов, А.А. Некрасов, Е.Г. Федотова, В.А. Иванов, В.Ю. Сидорова.- Дубровицы: изд. ООО «МУП Инфосервис», 2019.- 80с.

8. Каталог быков голштинской породы, оцененных в Ленинградской области по реализованной передающей способности.- С-Пб.: ФГБНУ ВНИИГРЖ, ОАО «Невское», ООО РЦ «Плинор", 2017.- Ч.2.- 272с.

9. Сакса Е.И. Основные принципы использования оцененных по геному и по качеству потомства быков голштинской породы в зависимости от их племенных качеств и схем подборов в высокопродуктивных стадах для повышения генетического потенциала животных (Наставления) / Е.И. Сакса, Е.С. Масленникова.- Пушкин:ВНИИГРЖ филиал ФГБНУ ФИЦ ВИЖ им. Л.К. Эрнста, 2020.- 20с.

10. Van Raden P.M. Genomic imputation and evaluation using nigh-density Holstein genotypes / P.M. Van Raden, D.J. Null, M. Sargolzaei, G.R. Wiggans, M.E. Tooker, J.B. Cole, T.S. Sonstegard, M.A. Faust, G.A. Doak // Jornal of dairy Science.- Vol.96.- N.1.2013.- P.668-678.

11. Каталог быков-производителей ОАО «ГЦВ» 2014 - 2015 гг. / Г.В. Ескин, Е.В. Федорова, Г.С. Турбина и др.- Подольск: Изд. ОАО «Головной центр по воспроизводству сельскохозяйственных животных», 2014.- 115с.

12. Генетические ресурсы ОАО «Московское» по племенной работе. Издание второе, перераб. и доп. / Т.Н. Тихонов, Ю.Н. Гулин, Н.П. Митюрев, С.В. Никитина и др.- М.: изд. ОАО «Московское» по племенной работе, 2014.- 184с.

13. Методика организации проверки и прогноза племенной ценности быков-производителей молочно-мясных пород по качеству потомства. СНПлем Р 11-96, МСX и продовольствия 
Российской Федерации, 25 декабря 1996 г.- М., 1996.- 15с.

14. Попов Н.А. Особенности потомства отечественного черно-пестрого скота от быков-производителей разных стран разведения голштинской породы / Н.А. Попов, Л.К. Марзанова, И.Н. Алексеева, В.А. Одиноких // Зоотехния.- 2013.- №2.C. $2-5$

15. Кузнецов В.М. Ограничение инбридинга в закрытых генофондных популяциях / В.М. Кузнецов, Н.В. Вахонина // Со-

\section{REFERENCES}

1. Herbut Piotr Forming of temperature-humidity index (THI) and milk production of cows in the free-stall barn during the period of summer heat / Piotr Herbut, Sabina Angrecka // Animal Science Papers and Reports.- 2012.- Vol. 30 (4) .- P.363-372.

2. Karlikov D.V. Coincidence of assessments of imported bulls of dairy breeds by pedigree and quality of offspring / D.V. Karlikov // In "Improving the breeding and productive qualities of domestic breeds of cattle." - M.: VNIIPlem, 1993. - P.96-103. (in Russ.)

3. Saks E.I. The effectiveness of the use of bulls, evaluated by different methods, in the improvement of highly productive herds / E.I. Sachs // Dairy and beef cattle breeding. - 2018.- No. 1.- P.5-9. (in Russ.)

4. Feedlot performance and carcass quality of spring finished Holstein steers fed whole corn and pelleted supplement with or without access to long hay / H. Chester-Jones, D.M. Ziegler, G.L. Dobberstein, P.T. Anderson // Minnesota Beef Res. Rpt .: Univ. Of Minnesota, St. Paul. - 2012.- B-401.- P.42-47.

5. Methodical instructions on the selection of bulls-producers of black-and-white breed to increase the level of milk productivity and milk quality of cows / N.A. Popov, A.N. Popov, L.K. Marzanova, V.Yu. Sidorova .- Dubrovitsy: GNU VIZH Russian Agricultural Academy, 2013 . - 72p. (in Russ.)

6. Methodical recommendations "Optimization of selection in herds of dairy cattle" / N.A. Popov, L.K. Marzanova, V.Yu. Sidorova .- Dubrovitsy: GNU VIZH Russian Agricultural Academy, 2008.48p. (in Russ.)

7. Guidelines for assessing the implementation of signs of growth, development and milk productivity in the offspring of bullsproducers / N.A. Popov, A.A. Nekrasov, E.G. Fedotov, V.A. Ivanov, V.Yu. Sidorov. - Dubrovitsy: ed. LLC "MUP Infoservice", 2019.- 80 p. (in Russ.)

8. Catalog of bulls of the Holstein breed, assessed in the Leningrad region for the realized transmission capacity. - St. Petersburg: FGBNU VNIIGZh, JSC "Nevskoe", LLC RC "Plinor", 2017.- Part 2.- 272 p. (in Russ.)

9. Saks E.I. The basic principles of using Holstein bulls, assessed временные проблемы диагностики, лечения и профилактики инфекционных болезней животных и птиц: Сб. науч. трудов.Екатеринбург, 2008.- С.268-271

16. Legarra A. Computational strategies for national integration of phenotypic, genomic, and pedigree data in a single-step best linear unbiased prediction / A. Legarra, V. Ducrocq // Jornal of dairy Science.- Vol.95.- N.8.- 2012.- P.4629-4645.

by the genome and the quality of the offspring, depending on thei breeding qualities and selection schemes in highly productive herds to increase the genetic potential of animals (Manual) / E.I. Saks, E.S. Maslennikov. - Pushkin: VNIIGZh branch of the FGBNU FITS VIZh them. OK. Ernst, 2020, 20 p. (in Russ.)

10. Van Raden P.M. Genomic imputation and evaluation using nigh-density Holstein genotypes / P.M. Van Raden, D.J. Null, M. Sargolzaei, G.R. Wiggans, M.E. Tooker, J.B. Cole, T.S. Sonstegard, M.A. Faust, G.A. Doak // Jornal of dairy Science.- Vol.96.- N.1.2013.- P.668-678.

11. Catalog of bulls-producers of JSC "GCV" 2014 - 2015. / G.V. Eskin, E.V. Fedorova, G.S. Turbina and others - Podolsk: Ed. JSC "Head center for the reproduction of farm animals", 2014.- $115 \mathrm{p}$. (in Russ.)

12. Genetic resources of JSC "Moskovskoe" for breeding work. Second edition, revised. and add. / T.N. Tikhonov, Yu.N. Gulin, N.P. Mityurev, S.V. Nikitin and others - M .: ed. JSC "Moskovskoe" for breeding work, 2014.- 184 p. (in Russ.)

13. Methodology for the organization of verification and forecast of the breeding value of bulls-producers of dairy and meat breeds by the quality of the offspring. SNPlem R 11-96, Ministry of Agriculture and Food of the Russian Federation, December 25, 1996 - M., 1996. - 15 p. (in Russ.)

14. Popov N.A. Features of the offspring of domestic blackand-white cattle from bulls-producers from different countries of breeding of the Holstein breed / N.A. Popov, L.K. Marzanova, I.N. Alekseeva, V.A. Lonely // Zootechnics.- 2013.- №2.- P.2-5. (in Russ.)

15. Kuznetsov V.M. Restriction of inbreeding in closed gene pool populations / V.M. Kuznetsov, N.V. Vakhonina // Modern problems of diagnosis, treatment and prevention of infectious diseases of animals and birds: Sat. scientific. works. - Yekaterinburg, 2008. - P. 268-271. (in Russ.)

16. Legarra A. Computational strategies for national integration of phenotypic, genomic, and pedigree data in a single-step best linear unbiased prediction / A. Legarra, V. Ducrocq// Jornal of dairy Science.- Vol.95.- N. 8.- 2012.- P.4629-4645.

\section{НОВОСТИ•НОВОСТИ•НОВОСТИ•НОВОСТИ}

\section{В Чувашии функционируют 243 пункта искусственного осеменения коров и телок}

В чувашских сельскохозяйственных организациях удельный вес племенного поголовья молочного скота превысил 44\%, сообщила пресс-служба регионального правительства. В настоящее время базу племенного животноводства Чувашии по крупному рогатому скоту представляют 18 племенных организаций, организация по искусственному осеменению сельскохозяйственных животных, региональный информационно-селекционный центр и 2 лаборатории селекционного контроля качества молока.

Зампредседателя кабмина Чувашской Республики - министр сельского хозяйства Сергей Артамонов отметил, что племенными заводами и репродукторами надаивается более $50 \%$ общего количества молока чувашских сельхозпредприятий. По его данным, в племенных хозяйствах республики организовано $100 \%$ искусственное осеменение коров и телок, что способствует формированию высокой степени генетического потенциала разводимого поголовья. Однако в частном секторе охват искусственным осеменением составляет $40 \%$, несмотря на то, что в Чувашии функционируют 243 пункта искусственного осеменения коров и телок. Решить эту задачу призваны созданные в этом году 10 мобильных пунктов искусственного осеменения сельскохозяйственных животных, которые начнут работу в конце августа. Мобильные пункты работают по принципу “скорой помощи" и оснащены всем необходимым оборудованием и средствами для искусственного осеменения, ухода и лечения животных в частных подворьях, пояснил министр.

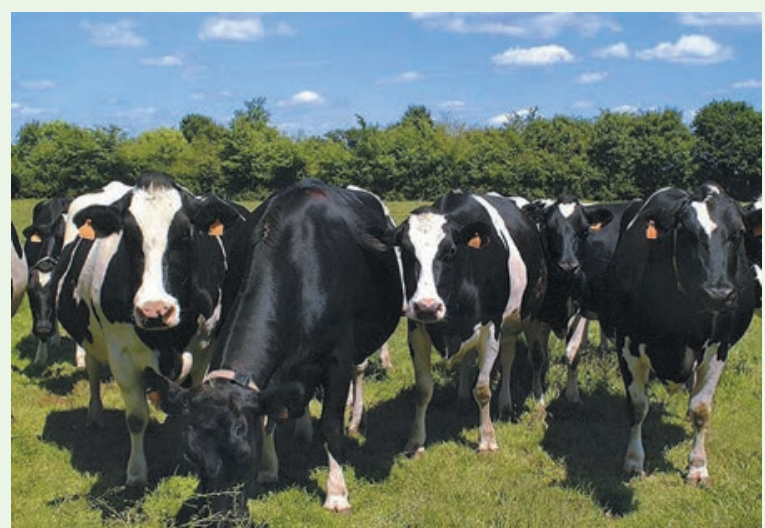

